\title{
Saudi Education Preparation Providers Achieving CAEP Standards: Challenges, Recommendations, and Solutions
}

\author{
Mohammed S. Alkathiri \\ Asst. Prof., Imam Abdulrahman bin Faisal University, Dammam, Saudi Arabia, \\ msalkathiri@iau.edu.sa
}

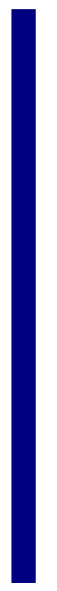

The aim of the Council for the Accreditation of Educator Preparation (CAEP) is to assure excellence in teacher preparation by focusing on quality and continuous improvement through peer review and outcomes-based accreditation. This paper draws conclusions and recommendations from the literature on the challenges facing Saudi education preparation providers (EPPs) in achieving CAEP standards. The researcher explored the accreditation system in Saudi Higher Education, and the challenges that EPPs face on the way to becoming accredited by the CAEP. The study of current issues for Saudi EPPs will help teacher educators become better prepared to meet the CAEP standards and to provide more effective teacher education for students. Each CAEP standard is briefly identified and followed by a discussion of related challenges in Saudi higher education that might influence EPPs' abilities to meet the standard. Recommendations and solutions are offered in each instance. By way of conclusion, three priority areas for improvement are identified: faculty involvement and development; strategies for quality assurance; and strategy for curriculum improvement.

Keywords: teaching, learning, CAEP standards, teacher education, teacher preparation, Saudi higher education

\section{INTRODUCTION}

Educational systems have the major responsibility of providing students with quality teaching and opportunities for learning. Students need educators with the abilities to help them develop higher-order thinking skills. Providing programs that have a positive impact on students is essential in the 21st century. Education preparation providers (EPPs) -also known as teacher training providers- must support and facilitate the efforts on their programs to achieve high quality standards. Meeting such standards will help them have a positive impact on students and be recognized for excellence in teaching and learning. "The Saudi education system has been criticized over many years because of its [low] quality, especially in terms of curriculum and the didactic nature of its pedagogy" (Smith \& Abouammoh, 2013, p. 6). It is urgent for Saudi EPPs to analyze

Citation: Alkathiri, M. S. (2020). Saudi Education Preparation Providers Achieving CAEP Standards: Challenges, Recommendations, and Solutions. International Journal of Instruction, 13(2), 649-662. https://doi.org/10.29333/iji.2020.13244a 
and improve the current situation. In this paper, I draw conclusions and recommendations from the literature on the challenges facing Saudi EPPs in their endeavors to achieve the standards set by the Council for the Accreditation of Educator Preparation (CAEP). The paper should help educators to become better prepared to meet the CAEP standards, and to train teachers more effectively.

\section{Saudi Higher Education}

The Kingdom of Saudi Arabia is one of the most oil-rich countries in the world. The country, because of its primarily dependence on oil revenues, needed a new vision to make change and find other resources to support the Saudi economy. Researchers have called for this transformation with the focus on the higher education sector as a major player in the future of the country (Onsman, 2010; Smith \& Abouammoh, 2013). To this end, government spending on higher education has already increased about threefold in five years. The current budget for higher education is about 12 percent of the national budget, which is approximately 160 billion U.S. dollars. Further, some universities have sought funds from non-government sources that now provide approximately 1.4 billion dollars for the sector (Smith \& Abouammoh, 2013). However, financial resources are not enough to ensure quality. Claims to quality have to be substantiated by outcomes (Terenzini, 2010).

People working in Saudi higher education desire to "achieve and maintain international quality standards and to contribute significantly to the future of our country" (Smith \& Abouammoh, 2013, p. v). This desire to assure quality in higher education has led to many initiatives such as the long-term strategic plan, named Afaq (an Arabic word for horizons), which works as a roadmap for all levels in Saudi higher education and focuses on quality and meeting world-class standards; the National Commission for Academic Assessment and Accreditation (NCAAA), which aims to work with universities to reach national quality standards in several aspects of their operations; and the National Centre for Assessment in Higher Education (NCAHE), which is in charge of secondary students' entry tests and selection for moving into higher education.

\section{Accreditation}

The NCAAA, established in 2004, is the single national accreditor for higher education universities and programs in Saudi Arabia (Onsman, 2010). Before 2009, individual universities were responsible for developing their own quality assurance programs and accreditation strategies (Darandari \& Cardew, 2013). In 2009, although many Saudi universities had already achieved or were working towards accreditation of their academic programs with international bodies (Smith \& Abouammoh, 2013), the government made it a legal requirement for all Saudi higher education institutions to be accredited for academic assessment and quality assurance purposes (Onsman, 2010). A message was sent to the institutions that lacked NCAAA standards, warning of the potential loss of funds and licensing (Onsman, 2010). Quality is defined by the NCAAA (2010) as "the value, worth, or standard of an institution or program in relation to generally accepted standards for an institution or program of its type" (p. 48). The Commission established standards for accreditation that are "relevant to Saudi Arabian 
requirements" and follow international good practice in accreditation and quality assurance in higher education (NCAAA, 2013, p. 1). There are two major types of accreditation: one for higher education institutions and another for higher education programs and courses (Darandari \& Cardew, 2013). An institution that meets NCAAA standards will be accredited for five years and will gain national recognition. However, if an institution is accredited by an international organization, that does not mean it is accredited by the NCAAA, or vice versa. There are eleven standards identified by the NCAAA (2013): (1) mission and objectives, (2) governance and administration, (3) management of quality assurance and improvement, (4) learning and teaching, (5) student administration and support services, (6) learning resources, (7) facilities and equipment, (8) financial planning and management, (9) faculty and staff employment processes, (10) research, and (11) institutional relationships with the community.

Evidence of successful practices by the higher education provider is required before accreditation is granted. Although the NCAAA does not explicitly indicate links between any of these standards, they do intersect and provide a basis for evaluation, improvement, and quality control in Saudi institutions and programs. The NCAAA standards are meant to provide a general framework by which institutions can assure quality. Beyond this, "institutions, units, programs and teachers are expected to achieve their own professional objectives while simultaneously meeting the quality standards and benchmarks set by the NCAAA" (Darandari \& Cardew, 2013, p. 108). Therefore, different colleges may consider adopting other standards, which are specific to their fields of study (such as CAEP standards for teacher education), while they also keep meeting the national quality standards of the NCAAA.

\section{Teacher education}

According to Alnassar and Dow (2013), 39 percent of all students in Saudi Arabia are enrolled in education fields, which is high compared to other areas of study, for example 6.3 percent in health sciences and 4.3 percent in engineering. It is important to assist students of education -students studying education- to acquire the skills they need to develop good learning approaches, ready for when they become school teachers, as "this new generation of teachers in schools will in turn set different emphases and a renewed culture of learning for their students" (Alnassar \& Dow, 2013, p. 52).

In 2007, the King Abdullah Project for the Development of Public Education was approved with a five-year budget of 3.1 billion dollars. Three of the main initiatives within this project are teacher training, curriculum review, and provision of technology for teaching and learning (Smith \& Abouammoh, 2013). The Saudi government and related ministries are committed to improving upon the current unsatisfactory state of education. Assuring the quality of teacher education programs by achieving high teaching and learning standards is foundational to the development of education.

\section{CAEP accreditation standards}

The Council for the Accreditation of Educator Preparation (CAEP) is a U.S. organization that formed out of the consolidation of the National Council for Accreditation of Teacher Education (NCATE) and the Teacher Education Accreditation 
Council (TEAC). The CAEP also formed a Committee on International Accreditation that works with international educator preparation providers outside the U.S. The aim of the CAEP is to assure excellence in teacher preparation, by focusing, through peer review and evidence-based accreditation, on quality and continuous improvement (CAEP, 2013). When EPPs apply for CAEP accreditation, they are asked to provide evidence of their work (e.g. self-assessment) that demonstrates they have met the CAEP standards, arranged within five large topics:

Standard 1: Content and Pedagogical Knowledge

Standard 2: Clinical Partnerships and Practice

Standard 3: Candidate Quality, Recruitment, and Selectivity

Standard 4: Program Impact

Standard 5: Provider Quality Assurance and Continuous Improvement

After peer review of the evidence and a site visit by CAEP assessors, EPPs will be granted accreditation for seven years if they have successfully met all the standards. Otherwise, they will be asked to make changes "based on evidence of candidate performance, use of data in program self-improvement, and EPP capacity and commitment to quality" (CAEP, 2013).

Table 1

Priority Areas for Improvement in Saudi EPPs in Order to Achieve CAEP Standards

\begin{tabular}{|c|c|c|c|}
\hline CAEP Standard & $\begin{array}{l}\text { Challenges facing Saudi } \\
\text { EPPs }\end{array}$ & Possible solutions & $\begin{array}{l}\text { Priority areas for } \\
\text { improvement }\end{array}$ \\
\hline $\begin{array}{l}\text { Standard 1: Content } \\
\text { and Pedagogical } \\
\text { Knowledge }\end{array}$ & $\begin{array}{l}\text { Teaching and learning } \\
\text { culture } \\
\text { Ineffective use of } \\
\text { technology } \\
\text { Low levels of research } \\
\text { activity }\end{array}$ & $\begin{array}{l}\text { Strategic leadership } \\
\text { Effective curriculum design } \\
\text { Strategy for improving research } \\
\text { activity } \\
\text { Professional development training } \\
\text { programs }\end{array}$ & $\begin{array}{l}\text { Faculty involvement and } \\
\text { development } \\
\text { Strategies for quality } \\
\text { assurance } \\
\text { Strategy for curriculum } \\
\text { improvement }\end{array}$ \\
\hline $\begin{array}{l}\text { Standard 2: Clinical } \\
\text { Partnerships and } \\
\text { Practice }\end{array}$ & $\begin{array}{l}\text { Low-quality pre-service } \\
\text { teacher practicum }\end{array}$ & $\begin{array}{l}\text { Implementation of outcomes- } \\
\text { based assessment } \\
\text { Use of students' satisfaction } \\
\text { surveys }\end{array}$ & $\begin{array}{l}\text { Strategies for quality } \\
\text { assurance } \\
\text { Strategy for curriculum } \\
\text { improvement }\end{array}$ \\
\hline $\begin{array}{l}\text { Standard 3: } \\
\text { Candidate Quality, } \\
\text { Recruitment, and } \\
\text { Selectivity }\end{array}$ & $\begin{array}{l}\text { Student admission } \\
\text { Workforce planning }\end{array}$ & $\begin{array}{l}\text { Higher admission requirements } \\
\text { Curriculum development }\end{array}$ & $\begin{array}{l}\text { Strategies for quality } \\
\text { assurance } \\
\text { Strategy for curriculum } \\
\text { improvement }\end{array}$ \\
\hline $\begin{array}{l}\text { Standard 4: Program } \\
\text { Impact }\end{array}$ & $\begin{array}{l}\text { Traditional approach to } \\
\text { assessment } \\
\text { Faculty concerns and } \\
\text { resistance }\end{array}$ & $\begin{array}{l}\text { Establishing educational } \\
\text { development centers } \\
\text { Faculty must have a major role in } \\
\text { the design and implementation of } \\
\text { the assessment in their programs }\end{array}$ & $\begin{array}{l}\text { Faculty involvement and } \\
\text { development } \\
\text { Strategies for quality } \\
\text { assurance } \\
\text { Strategy for curriculum } \\
\text { improvement }\end{array}$ \\
\hline $\begin{array}{l}\text { Standard 5: Provider } \\
\text { Quality Assurance } \\
\text { and Continuous } \\
\text { Improvement }\end{array}$ & $\begin{array}{l}\text { Lack of valid } \\
\text { information } \\
\text { Lack of ongoing process } \\
\text { of review and evaluation } \\
\text { Feeling accreditation to } \\
\text { be a painful obligation }\end{array}$ & $\begin{array}{l}\text { Clear strategy to determine } \\
\text { information available and } \\
\text { effectiveness of information unit's } \\
\text { activities at higher education } \\
\text { institutions } \\
\text { Assessment as a tool to improve } \\
\text { the quality of student learning }\end{array}$ & $\begin{array}{l}\text { Strategies for quality } \\
\text { assurance }\end{array}$ \\
\hline
\end{tabular}




\section{METHOD}

For the purposes of this systematic review, I studied the CAEP's (2013) descriptions of the five standards and developed a list of challenges relating to each of them. After that, I conducted a literature search based on the list of challenges, using the Saudi Digital Library (SDL), sdl.edu.sa. The SDL allows searching among 71,390 databases. My literature search was focused on articles pertinent to the context of Saudi teacher education. The challenges facing Saudi EPPs that I addressed in the literature are shown in Table 1. Then I studied the possible solutions proposed in the literature to overcome the challenges. Finally, I identified the fundamental priorities for Saudi EPPs to address and consider.

\section{FINDINGS AND DISCUSSION}

In each of the following sections, one of the CAEP standards is briefly identified and then followed by a discussion of some of the related challenges and issues in Saudi higher education that might affect EPPs' ability to meet it. It is important for the future of Saudi EPPs that they should have effective, high-standard teacher preparation programs. Understanding the CAEP standards, related challenges, and possible solutions will help the EPPs to set priorities and make changes in order to achieve these standards.

\section{Standard 1: Content and Pedagogical Knowledge}

EPPs are responsible for ensuring that graduates have deep understandings of their respective disciplines, and that they can promote students' abilities to acquire the knowledge and skills needed for their futures (e.g. in college, or careers). Under this standard, the CAEP (2013) has highlighted five main recommendations for EPPs to take into consideration when applying for accreditation. A shortened version of these recommendations is as follows: (1) students in the program are at an appropriate level of progression in four main categories: the learner and learning, content, instructional practice, and professional responsibility; (2) graduates from the program use research and evidence in order to develop an understanding of teaching as a profession, to measure their P-12 students' learning, and to reflect on their own teaching practices; (3) graduates can apply content and pedagogical knowledge; (4) graduates demonstrate skills and commitment in assisting P-12 students' preparedness to meet rigorous collegeand career-ready standards; and (5) graduates are able to apply technology in their practices of teaching, from design to assessment, in order to engage students in learning and to enrich their own professional practices.

These recommendations cover many different aspects of content and pedagogical knowledge required in teacher preparation programs, such as knowledge of learners (including, more specifically, learners' existing knowledge and experience, learning processes and development, and individual differences and needs) and knowledge of how to teach effectively (including preparation and teaching design, facilitation, collaboration, communication, and relating to students' families).

\section{Challenges}

It is essential for new teachers to be well-prepared in terms of content, pedagogical knowledge, and key skills such as effective communication and use of technology. They 
will then be effective teachers who can design, implement, communicate, evaluate, and improve their lessons. However, some obstacles-like the traditional teaching and learning culture, a failure to use technology productively in teaching, and a low level of academic research into teacher education - can negatively affect efforts to prepare effective teachers.

Teaching and learning culture. In Saudi universities, the teaching and learning culture is ineffective, focusing on rote learning and lacking in "interactive delivery of knowledge," leading to the limiting of students' critical thinking abilities and of their acquisition of new skills (Smith \& Abouammoh, 2013). According to McMullen (2014), Saudi students are interested in test results more than learning, regardless of teaching and pedagogical practices. Unconscious traditional beliefs still exist in Saudi Arabia about teachers (e.g. they are the main source for knowledge) and about methods of teaching (Robertson and Al-Zahrani, 2012). Aytekin et al. (2012) found evidence that confirmed "the need to change school culture, classroom pedagogy to support enthusiastic and innovation in teaching and learning" (p.292).

Ineffective use of technology. Much research shows a positive tendency among Saudi teachers to use technology, such as computers and interactive whiteboards, in their teaching. However, according to Aytekin et al. (2012), a large number of secondary school teachers were not able to use interactive whiteboards effectively. Also, Robertson and Al-Zahrani (2012) found gaps between "rhetoric and practice" when considering the integration of technology into Saudi higher education, especially teacher education. This reflects the fact that there are good intentions to integrate technology in teacher education, but, unfortunately, the level of practical implementation is inadequate to transform these intentions into reality.

Low levels of research activity. According to Al-Ohali and Shin (2013), the level of research activity in Saudi higher education is considered low by international standards. They reported that there was no clear strategy in place for improving Saudi academics' research, and much reliance on researchers from other countries. Alharbi (2009) also indicated that research productivity was relatively low and educational research in particular had limited funding in Saudi Arabia. In addition, Borg and Alshumaimeri (2012) found that the support provided to teacher educators in Saudi Arabia was inadequate considering the level of research productivity expected from them. Borg and Alshumaimeri (2012) identified "modest levels of research activity and also suggested that these individuals [teacher educators] held largely technical views of what research is" (p. 347). The reluctance of Saudi professors to conduct research, for whatever reason, negatively affects the ability of EPPs to provide students with research knowledge and skills. As a result, graduates with poor research skills have difficulties understanding the profession and improving their teaching.

\section{Recommendations and possible solutions}

I found four possible solutions in the literature that could contribute to improved outcomes in higher education programs, especially in teacher preparation: strategic 
leadership, effective curriculum design, strategy for improving research activity, and development training programs.

Strategic leadership. Robertson and Al-Zahrani (2012) assert the need for sympathetic and strategic leadership. A clear vision and strategic leadership are needed to transform teacher education into a new model for the $21^{\text {st }}$ century. New leaders have to challenge the current traditional teaching and learning culture and promote the effective use of technology. "The call for $21^{\text {st }}$ century knowledge frameworks largely rests on the assertion that education has failed to prepare students for the demands of the $21^{\text {st }}$ century" (Kereluik et al., 2013, p. 128).

Effective curriculum design. Curricula should be developed to enhance $21^{\text {st }}$ century skills. "Critical thinking and problem solving are considered by many to be the new basics of $21^{\text {st }}$ century learning" (Trilling \& Fadel, 2009, p. 50). Well-designed curricula will provide students with opportunities to master content, sharpen teaching skills, and develop other professional skills like communication and ethics. In addition, innovative pedagogies that focus on the student will contribute to changing the traditional teaching and learning culture.

Strategy for improving research activity. The CAEP considers research to be an essential skill that graduates from teacher education should appropriately demonstrate. Research is key to a student-centered approach to learning, where students use the research process to find results and make meaning of them. "Postsecondary higher education institutions are moving toward learner-centered designs, shifting focus to process and not product" (Irvine, Code, \& Richards, 2013, p. 173). Teaching research skills will help students become more engaged in their learning. Also, it will help them develop critical thinking skills, so that in the future they become able to evaluate both their own teaching, and the needs of their own students. A clear strategy for improving research activity should analyze and evaluate the current situation and provide an action plan that sets a time frame for improvement. This does not mean it should be rushed; it has to be established carefully.

Professional development training programs. These are required to present important pedagogical topics and terms such as student-centered and outcome-based teaching and learning. Furthermore, Aytekin et al. (2012), as well as Al-Ghreimil and Colbran (2013), found that professional development training programs were necessary for teachers to improve their teaching skills. It is important to have educational experts develop and provide such training.

\section{Standard 2: Clinical Partnerships and Practice}

According to the CAEP (2013), EPPs have to ensure that graduates from their programs have experienced effective clinical partnerships and practice during preparation in order to acquire the knowledge and skills needed to succeed in teaching P-12 students. Highquality clinical partnerships and practice give EPPs opportunities to improve graduates' preparation by linking theory and practice, ensuring that graduates demonstrate knowledge of content and pedagogy. 


\section{Challenges}

The weak teaching competencies of graduates from some programs are a serious issue. Low-quality pre-service teacher practicum experiences make it difficult for EPPs to meet CAEP standards and, more importantly, leave students unsatisfied with their clinical experiences on a program. The practicum experience should provide opportunities for students to teach and practice what they have learned. It is designed to equip them with the knowledge and skills they need to have a positive impact as teachers in real classrooms. Alheezan (2009) surveyed 203 art-education teachers and administrators in Saudi Arabia and reported that 33.5 percent of the teachers and 92 percent of the administrators thought that art-education courses were not beneficial to them with no high-quality pre-service teacher practicum. Although "professional development for classroom teachers . . . remains a critical dimension of a profession coping with ever-changing curricula and pedagogical knowledge" (Mueller \& Welch, 2006, p. 143), many teachers in Saudi Arabia have never had pre-service training. Moreover, those teachers are less interested in taking any professional development training to enhance their skills (Khan, 2011). Graduates with low-quality practicum experiences will lack knowledge of content and pedagogy, as a result, have a negative impact on students.

\section{Recommendation and possible solution}

EPPs are responsible for providing students with effective practicum experiences where they can demonstrate their learning. The existing designs and policies for pre-service teacher practicum experiences need to be evaluated and improved. Improvements in higher education have to focus on enhancing students' overall development (Astin, 1993). EPPs must implement outcomes-based assessment of pre-service teacher practicum experiences, as well as student satisfaction surveys to find out what is needed for successful improvement.

\section{Standard 3: Candidate Quality, Recruitment, and Selectivity}

The CAEP (2013) requires that EPPs not only take responsibility for ensuring the quality of their students and graduates during a program, but also before and after the program. EPPs are responsible for selecting students who have the potential to succeed in programs, become effective teachers, and meet employment needs. First, in order to ensure high levels of academic achievement, the CAEP requires EPPs to set high admissions requirements (e.g. student performance in ACT, SAT, or GRE must be at least in the $50^{\text {th }}$ percentile). Second, it is important for EPPs to address different "hardto-staff" fields (e.g. STEM subjects and teaching students with disabilities), and the employment needs in different geographical areas (e.g. community, state, or regional). Also, it is essential to have plans and goals for recruiting students from different backgrounds and populations. Third, during preparation, EPPs must have criteria to measure students' progress and development from admission through graduation. Fourth, before EPPs award certificates, they have to ensure that graduates meet standards for knowledge of content and pedagogy, as well as professional standards with respect to ethics and policies. 


\section{Challenges}

"The Ministry of Education has started working to create standardized tests and assessment tools to examine teachers' preparation and competencies in different subjects" (Alnahdi, 2014, p. 3). However, there are other areas needing to be addressed and evaluated to ensure quality outcomes from teacher preparation programs. For example, student admission and workforce planning are two areas that need to be reviewed.

Student admission. The current admission requirements of EPPs are very low compared to CAEP requirements. Teachers in Saudi Arabia have life-long, government jobs, so many people who are not interested in education choose to attend teacher preparation programs because of the job security (Alnahdi, 2014).

Workforce planning. "Learning is also said to be high quality if learning is capable to facilitate students to prepare themselves as individuals who are able to compete in employment after graduation" (Rahardjanto, Husamah, \& Fauzi, 2019, p. 180). According to Smith and Abouammoh (2013), current workforce planning in Saudi Arabia has serious issues, including around curricula and career guidance. There is a gap between curricula and future employment needs. The curricula are not consistent with workforce needs while career guidance depends on unrealistic student wishes.

\section{Recommendations and possible solutions}

In order to ensure quality outcomes, admission requirements must be higher. Education programs should not attract people who lack an interest in teaching (Alnahdi, 2014). Higher admission requirements would help increase the number of students who have the potential to succeed in their studies (CAEP, 2013). Also, curriculum development has to reflect future workforce needs. Kereluik et al. (2013) state that it has "become increasingly evident that the labor force required by an increasingly globalized economy requires an altogether different model of education - one that transcends the $20^{\text {th }}$ century skills of repetition, basic applied knowledge, and limited literacy" (p. 128). According to the Saudi Ministry of Economy and Planning (2010), higher education prepares skilled graduates to contribute to the Saudi economy after receiving their education. "Career guidance should seek to direct students into study [programs] that will lead to genuine employment outcomes" (Smith \& Abouammoh, 2013, p. 176).

\section{Standard 4: Program Impact}

According to the CAEP (2013), EPPs must be satisfied with the preparation of their graduates and provide evidence that the graduates will have a positive impact on P-12 students' learning and development. EPPs use different measures, such as value-added measures and student-growth percentiles, in order to determine this. Also, EPPs use structured and validated instruments (e.g. surveys) to prove that graduates have the knowledge and skills needed to become effective teachers. Further, EPPs use valid and reliable data to show that employers and the graduates themselves are satisfied with the preparation program because it equips graduates with the knowledge and skills needed to work effectively with P-12 students. 


\section{Challenges}

In order to increase students' learning and effectively measure program impact, EPPs must strongly emphasize "a culture of assessment" (Cydis, 2014). Their efforts are likely to be obstructed by traditional approaches to assessment, as well as by concerns and resistance from faculty.

Traditional approaches to assessment. Saudi higher education has been relying on traditional methods of assessment that are teacher-centered for many years. Darandari and Murphy (2013) put together an overview of assessment in Saudi higher education and have highlighted some major issues such as the failure to implement outcomesbased assessments and the lack of assessment skills among faculty. Due to insufficient use of student-centered and outcomes-based assessments, ineffective traditional learning assessments (e.g. summative norm-referenced assessments) remained dominant, which focus on ranking students instead of assessing their learning (Alwadai, 2014; Hamdan, 2014; Smith \& Abouammoh, 2013). Also, the lack of educational skills among faculty, especially on assessment, contributes to the poor quality of teaching and learning. Some faculty members are not able to use assessment to improve their teaching. In other cases, assessment models are designed separately from the curriculum.

Faculty concerns and resistance. Faculty members have some serious concerns about the methods of evaluation of student progress being used on their programs, and whether such progress is really measurable. Some of the issues are related to the nature, sources, and quality of the evidence on which assessments are based (Smith \& Abouammoh, 2013). Also, faculty members may show resistance to assessment for reasons such as the lack of a defining purpose to it, a lack of standards for evaluation, their own poor level of knowledge and skills for assessment, and a lack of support and training (Al-Ghamdi \& Tight, 2013).

\section{Recommendations and possible solutions}

To change the traditional assessment culture in Saudi universities, it is important to establish educational development centers with high-quality staff. These centers will become resources for faculty's pedagogical development in general and their development of assessment skills in particular. Also, faculty must play a major role in the design and implementation of the assessment on their programs, and must be especially involved in the interpretation of results and generation of recommendations for improvement (Smith \& Abouammoh, 2013).

\section{Standard 5: Provider Quality Assurance and Continuous Improvement.}

EPPs must continuously assure the quality of their programs. They have to show their ability to use the data from several different measures and evaluations as tools for ongoing improvement (CAEP, 2013). This will support graduates and have a positive impact on students' learning and development. One form of evidence is the data from program evaluations by stakeholders (e.g. alumni and employers). The process of evaluation has to be continuous and systematic in order to meet the standard.

\section{Challenges}


I found three challenges that might affect EPPs' ability to assure quality and continuous improvement: the lack of availability of information, the lack of ongoing processes of evaluation, and the feeling that accreditation is a painful obligation.

Lack of information. Continuous development requires valid data that can be used to evaluate the current situation and set plans for improvement. With weak or no information, evaluation of the work already done will be a challenge, if it is possible at all. The situation of Saudi higher education in terms of availability of information is quite unique: much information is available, but with a questionable value to make decisions based upon it (Smith \& Abouammoh, 2013). Saudi higher education had no clear strategy for information collection and analysis for many years, which meant that the collection of information followed no common standards and happened in various different forms. These problems are still ongoing, and the situation has not changed for the better more recently. Also, most of the data available is quantitative, and little if any qualitative data is collected or provided by universities (Smith \& Abouammoh, 2013).

No ongoing process of review and evaluation. Smith and Abouammoh noted in 2013 that the comprehensive strategic plan for Saudi higher education needed improvement because it lacked guidelines for an ongoing process of review and evaluation, and it was "weak on specific detail about the strategies and action plans necessary to convert the [higher education] vision into reality" (p. 6).

Feeling accreditation to be a painful obligation. Accreditation is a process for learning about our work, programs, achievements, and expectations. It has to be done carefully and continuously: "The assessment of student outcomes . . . is not something that can be done quickly or casually" (Terenzini, 2010, p. 45). When receiving accreditation is seen as a goal in and of itself and "something to be done as quickly and as painlessly as possible . . . significant opportunities to enhance educational programs are likely to be lost" (Terenzini, 2010, p. 30).

\section{Recommendations and possible solutions}

It is important to understand that assessment implementation is not a goal in itself, but a tool that should be used to improve the quality of student learning. EPPs have to show their ability to use the data from different measures and evaluations as tools for ongoing improvement. EPPs must have a clear strategy to determine what type of information is available and the best way to use it. Smith and Abouammoh (2013) recommended that Saudi institutions should survey all their academic and administrative offices in order to identify the information already on hand about students and the effectiveness of their information unit's activities.

\section{CONCLUSION}

According to Alharbi (2009), “deficiencies in students' training and their inadequate job-related skills reflect the moderate standard of Saudi higher education in comparison to Western systems" (p. 281). It would be challenging for Saudi EPPs to meet CAEP standards without resolving current issues. This paper should not discourage Saudi institutions from working to get accredited. In fact, it is intended to help them by 
identifying some of the challenging areas addressed in the literature. Although no researchers have previously studied the level of readiness of Saudi EPPs to achieve CAEP standards, the literature provides great insights into what areas of Saudi higher education are challenging and how to improve them. When such challenges are considered, institutions will be better prepared to overcome them and meet CAEP standards. To accomplish this purpose, it is important to identify issues and priorities, which will help with focusing on the urgent issues, and to go through the process of development step by step. The purpose of gaining accreditation is to improve the quality of programs provided.

As shown in Table 1, the literature review presented in this paper reveals three fundamental priorities for Saudi EPPs to consider: First, the transformation to a new model of teaching and learning requires faculty involvement and development. "Effective pedagogical change can only occur if the academics themselves believe in that change" (Smith \& Abouammoh, 2013, p. 186). An essential part of promoting faculty involvement is providing educational development programs for academics who lack pedagogical knowledge and skills. Moreover, "providing some workshops and lectures is not expected to change faculty members' way of teaching overnight. It [professional development] is a continuous commitment that they have to undertake" (Al-Hattami, Muammar \& Elmahdi, 2013, p. 44). Second, having and developing strategies for quality assurance must become a priority for EPPs. An important part of quality assurance is a clear mechanism for data collection and analysis in order to have accurate and valid information about programs and students' learning. Valid and reliable data is not only essential in order to assure quality, but also to inform stakeholders of existing teaching and learning practices. Quality assurance strategies will assist efforts towards planning and improving programs. Third, a strategy for curriculum improvement is needed. Traditional curricula negatively affect both professors and students. For more than one CAEP standard, the curriculum is a direct or an indirect challenge. Successful implementation of these three priorities would boost the ability of Saudi higher education, EPPs in particular, to provide high-quality teacher education programs that meet CAEP standards, students' needs, and employers' expectations.

\section{REFERENCES}

Alghamdi, A. K., \& Deraney, P. (2013). Effects of teaching critical thinking to Saudi female university students using a stand-alone course. International Education Studies, 6(7), 176-188. doi:10.5539/ies.v6n7p176.

Al-Ghamdi, S., \& Tight, M. (2013). Selecting and developing high-quality academic staff. In L. Smith, \& A. Abouammoh (Eds.), Higher education in Saudi Arabia: Achievements, challenges and opportunities (pp. 83-93). London: Springer. doi:10.1007/978-94-007-6321-0_8.

Alharbi, M. (2009). Evaluation of quality: Student perceptions. The International Journal of Learning, 16(9), 281-296. 
Al-Hattami, A. A., Muammar, O. M., \& Elmahdi, E. A. (2013). The need for professional training programmes to improve faculty members teaching skills. European Journal of Research on Education, 1(2), 39-45.

Alheezan, A. (2009). Examining art education in boys' middle schools in Saudi Arabia in Riyadh (Unpublished doctoral dissertation). Florida State University, United States.

Alnahdi, G. H. (2014). Educational change in Saudi Arabia. Journal of International Education Research, 10(1), 1-6.

Alnassar, S. A., \& Dow, K. L. (2013). Delivering high-quality teaching and learning for university students in Saudi Arabia. In L. Smith, \& A. Abouammoh (Eds.), Higher education in Saudi Arabia: Achievements, challenges and opportunities (pp. 49-60). London: Springer. doi:10.1007/978-94-007-6321-0_5.

Al-Ohali, M., \& Shin, J. (2013). Knowledge-based innovation and research productivity in Saudi Arabia. In L. Smith, \& A. Abouammoh (Eds.), Higher education in Saudi Arabia: Achievements, challenges and opportunities (pp. 95-102). London: Springer. doi:10.1007/978-94-007-6321-0_9.

Alwadai, M. A. (2014). Islamic teachers' perceptions of improving critical thinking skills in Saudi Arabian elementary schools. Journal of Education and Learning, 3(4), 37-48. doi:10.5539/jel.v3n4p37.

Astin, A. (1993). What matters in college? San Francisco: Jossey-Bass.

Aytekin, I., Abanmy, F., Hussein, H., \& Alsaadany, M. (2012). Saudi secondary school teachers' attitudes towards using interactive whiteboard in classrooms. The Turkish Online Journal of Educational Technology, 11(3), 286-296.

Bell, S. (2010). Project-based learning for the $21^{\text {st }}$ century: Skills for the future. The Clearing House, 83, 39-43. doi:10.1080/00098650903505415.

Borg, S., \& Alshumaimeri, Y. (2012). University teacher educators' research engagement: Perspectives from Saudi Arabia. Teaching and Teacher Education, 28, 347-356. doi:10.1016/j.tate.2011.10.011.

Council for the Accreditation of Educator Preparation. (2013). CAEP accreditation standards and evidence: Aspirations for educator preparation. Retrieved 17 March, 2019 from http://caepnet.org/ /media/Files/caep/standards/commrpt.pdf?la=en

Cydis, S. (2014). Fostering competencies in future teachers: A competency-based approach to teacher education. Creative Education, 5, 1148-1159. doi:10.4236/ce.2014.513130.

Darandari, E., \& Cardew, P. (2013). Accreditation and quality assurance. In L. Smith, \& A. Abouammoh (Eds.), Higher education in Saudi Arabia: Achievements, challenges and opportunities (pp.103-115), London:Springer. doi:10.1007/978-94-007-6321-0_10.

Hamdan, A. (2014). The road to culturally relevant pedagogy: Expatriate teachers' pedagogical practices in the cultural context of Saudi Arabian higher education. McGill Journal of Education, 49(1), 201-226. doi:10.7202/1025778ar. 
Irvine, V., Code, J., \& Richards, L. (2013). Realigning higher education for the $21^{\text {st }}$ century learner through multi-access learning. Journal of Online Learning \& Teaching, 9(2), 172-186.

Kereluik, K., Mishra, P., Fahnoe, C., \& Terry, L. (2013). What knowledge is of most worth: Teacher knowledge for 21st century learning. Journal of Digital Learning in Teacher Education, 29(4), 127-140. doi:10.1080/21532974.2013.10784716.

Khan, I. A. (2011). An analysis of learning barriers: The Saudi Arabian context. International Education Studies, 4(1), 242-247. doi:10.5539/ies.v4n1p242.

McMullen, M. G. (2014). The value and attributes of an effective preparatory English program: Perceptions of Saudi university students. English Language Teaching, 7(7), 131-140. doi:10.5539/elt.v7n7p131.

Mueller, A., \& Welch, M. (2006). Classroom-based professional development: Teachers' reflections on learning alongside students. The Alberta Journal of Educational Research, 52(2), 143-157.

National Commission for Academic Accreditation and Assessment. (2010). Handbooks 1-3. Riyadh: NCAAA.

National Commission for Academic Accreditation and Assessment. (2013). Quality assurance and accreditation in Saudi Arabia. Riyadh: NCAAA.

Onsman, A. (2010). Dismantling the perceived barriers to the implementation of national higher education accreditation guidelines in the Kingdom of Saudi Arabia. Journal of Higher Education Policy and Management, 23(5), 511-519. doi:10.1080/1360080X.2010.511123.

Rahardjanto, A., Husamah, \& Fauzi, A. (2019). Hybrid-PjBL: Learning Outcomes, Creative Thinking Skills, and Learning Motivation of Preservice Teacher. International Journal of Instruction, 12(2), 179-192. https://doi.org/10.29333/iji.2019.12212a.

Rahman, M., \& Al Haisoni, E. (2013). Teaching English in Saudi Arabia: Prospects and challenges. Academic Research International Journal, 4(1), 112-118.

Robertson, M., \& Al-Zahrani, A. (2012). Self-efficacy and ICT integration into initial teacher education in Saudi Arabia: Matching policy with practice. Australasian Journal of Educational Technology, 28(7), 1136-1151. doi:10.14742/ajet.793.

Saudi Ministry of Economy and Planning. (2010). Ninth development plan. In Main directions of the ninth development plan ( $\mathrm{pp}$. 25-41). Retrieved from https://www.mep.gov.sa/en/AdditionalDocuments/PlansEN/9th/Ninth\%20Development $\% 20$ Plan\%20-\%20Chapter\%202\%20-

\%20Main\%20Directions\%20Of\%20The\%20Ninth\%20Development\%20Paln.pdf.

Smith, L., \& Abouammoh, A. (2013). Higher education in Saudi Arabia: Achievements, challenges and opportunities. London: Springer. doi:10.1007/978-94-007-6321-0.

Terenzini, P. T. (2010). Assessment with open eyes: Pitfalls in studying student outcomes. New Directions for Institutional Research, 23(5), 29-46. doi:10.1002/ir.329. 